\title{
Creatine kinase-MB elevation after percutaneous coronary intervention predicts adverse outcomes in patients with acute coronary syndromes
}

\author{
M.T. Roe ${ }^{a *}$, K.W. Mahaffey ${ }^{a}$, R. Kilaru ${ }^{a}$, J.H. Alexander ${ }^{a}$, K.M. Akkerhuis ${ }^{b}$, \\ M.L. Simoons ${ }^{b}$, R.A. Harrington ${ }^{a}$, B.E. Tardiff ${ }^{a}$, C.B. Granger ${ }^{a}$, \\ E.M. Ohman ${ }^{a}$, D.J. Moliterno ${ }^{f}$, A.M. Lincoff ${ }^{c}$, P.W. Armstrong ${ }^{d}$, \\ F. Van de Werf ${ }^{e}$, R.M. Califf ${ }^{a}$, E.J. Topol ${ }^{c}$ \\ ${ }^{a}$ Duke Clinical Research Institute, Durham, North Carolina, USA \\ b University Hospital, Rotterdam, The Netherlands \\ 'Cleveland Clinic Foundation, Cleveland, Ohio, USA \\ 'University of Alberta, Edmonton, Canada \\ e Catholic University Hospital, Leuven, Belgium \\ ${ }^{\mathrm{f}}$ University of Kentucky, Lexington, Kentucky, USA
}

Received 20 February 2003; received in revised form 9 October 2003; accepted 4 December 2003

This paper was guest edited by Prof. Bernard J. Gersh, Mayo Clinic

\author{
KEYWORDS \\ Acute coronary syndromes; \\ Prognosis; \\ Creatine kinase; \\ Biomarkers; \\ Percutaneous coronary \\ interventions
}

\begin{abstract}
Aim To study the relationship between outcomes and peak creatine kinase (CK)-MB levels after percutaneous coronary intervention $(\mathrm{PCI})$ in patients with non-ST-segment elevation acute coronary syndromes (NSTE ACS).

Methods and results Peak CK-MB ratios (peak CK-MB level/upper limit of normal [ULN]) after PCI were analysed in 6164 patients with NSTE ACS from four randomized trials who underwent in-hospital $\mathrm{PCl}$. We excluded 696 patients with elevated $\mathrm{CK}$ or CK-MB levels $<24 \mathrm{~h}$ before $\mathrm{PCl}$; the primary analysis included 2384 of the remaining 5468 patients $(43.6 \%$ ) with CK-MB levels measured $\leq 24 \mathrm{~h}$ after $\mathrm{PCl}$. The incidence of in-hospital heart failure $(0.1 \%, 0.8 \%, 3.4 \%, 4.1 \%$, and $6.1 \% ; P<0.001)$, arrhythmias $(0.8 \%, 1.9 \%, 6.9 \%, 4.1 \%$, and $7.9 \% ; P<0.001)$, cardiogenic shock $(0.1 \%, 1.3 \%, 2.0 \%$, $2.3 \%$, and $2.6 \% ; P=0.004)$, and mortality through 6 months $(2.1 \%, 2.4 \%, 4.9 \%, 4.1 \%$, and $5.7 \%, P=0.005)$ was increased with peak CK-MB ratios of $0-1,1-3,3-5,5-10$, and $>10 \times U L N$, respectively. The continuous peak CK-MB ratio after $\mathrm{PCl}$ significantly predicted adjusted 6-month mortality (risk ratio, 1.06 per unit increase above ULN; 95\% confidence interval, 1.01-1.11; $P=0.017)$.

Conclusions Greater CK-MB elevation after $\mathrm{PCl}$ is independently associated with adverse outcomes in NSTE ACS. These results underscore the adverse implications of elevated $\mathrm{CK}-\mathrm{MB}$ levels after $\mathrm{PCI}$ in this high-risk population.

(C) 2003 Published by Elsevier Ltd on behalf of The European Society of Cardiology.
\end{abstract}

\footnotetext{
* Correspondence to: Matthew T. Roe, MD, MHS, Duke Clinical Research Institute, P.O. Box 17969, Durham, NC 27715 USA. Tel: +919-668-8959; fax: +919-668-7059

E-mail address: roe00001@mc.duke.edu (M.T. Roe).
}

\section{Introduction}

Elevated cardiac enzyme levels can be detected in 10$20 \%$ of patients undergoing percutaneous coronary intervention $(\mathrm{PCl})$, but the clinical significance of myocardial 
necrosis after $\mathrm{PCl}$ and the definition of periprocedural myocardial infarction (MI) remain controversial. ${ }^{1-3}$ Multiple studies have shown an increased risk of mortality with elevated levels of creatine kinase (CK) and CK-MB isoenzymes after $\mathrm{PCl}^{4-7}$ Although patients with acute coronary syndromes (ACS) have a higher risk of procedural complications during $\mathrm{PCl}$ than patients undergoing elective coronary intervention, the incidence, definition, and prognostic implications of periprocedural cardiac enzyme elevations in patients with ACS have not been well-studied. ${ }^{8,9}$ Because almost one-fourth of patients with ACS undergo $\mathrm{PCl}$ during their initial hospitalization, and non-fatal ischaemic events are often incorporated into definitions for clinical trial end-points, cardiac enzyme elevations after $\mathrm{PCl}$ could significantly influence individual outcomes and the results of trials that include patients with ACS. ${ }^{10-13}$

The Global Use of Strategies To Open occluded coronary arteries in acute coronary syndromes (GUSTO-Illb), Platelet glycoprotein in Unstable angina Receptor Suppression Using Integrilin Therapy (PURSUIT), Platelet IIb/ Illa Antagonism for the Reduction of Acute coronary syndrome events in a Global Organization Network (PARAGON-A), and PARAGON-B trials evaluated new antithrombotic and antiplatelet therapies for patients with non-ST segment elevation (NSTE) ACS. We evaluated patients from these trials who underwent $\mathrm{PCl}$ during the initial hospitalization to assess the impact of periprocedural CK-MB elevations on clinical outcomes.

\section{Methods}

\section{Study population}

The enrolment criteria for these trials were similar across trials. ${ }^{10-12,14}$ Patients with NSTE ACS were enrolled if they had ischaemic chest pain within 12-24 h before presentation with electrocardiographic (ECG) signs of ischaemia or elevated serum cardiac markers, including troponin I or T or CK-MB. The subgroup of patients in the GUSTO-IIb trial with persistent STsegment elevation was not evaluated. The institutional review committees of all participating hospitals approved the study protocols, and all subjects gave informed consent.

\section{Randomization and treatment}

In GUSTO-IIb, patients were randomized to receive intravenous unfractionated heparin or recombinant hirudin for $3-5$ days. ${ }^{10}$ In PURSUIT, patients were randomized in a double-blind fashion to receive placebo or one of two doses of the platelet glycoprotein Ilb/Illa inhibitor eptifibatide for 3-4 days. ${ }^{11}$ In PARAGON-A, patients were randomized in a $2 \times 2$ factorial design to receive low-dose lamifiban (a glycoprotein Ilb/Illa inhibitor), high-dose lamifiban with intravenous heparin, or placebo with intravenous heparin for 3-5 days. ${ }^{12}$ In PARAGON-B, patients were randomized to receive lamifiban or placebo for 3-5 days, and study drug was adjusted for renal function. ${ }^{14}$

\section{Concomitant treatment}

Aspirin (80-325 mg daily) was recommended for all trial patients. Heparin was recommended for all patients in PURSUIT and PARAGON-B but was not required. ${ }^{11,14}$ Heparin use was determined by randomized treatment assignment in GUSTO-IIb and PARAGON-A. Other medications were given at the discretion of the treating physicians. Decisions about coronary angiography, $\mathrm{PCl}$, and bypass surgery were not protocol-mandated and were made by the treating physician. Routine surveillance of CK-MB levels was strongly recommended at enrolment, after recurrent ischaemic events, and after revascularization ( $\mathrm{PCl}$ or bypass surgery) but was not mandated by the study protocols. CK-MB levels were analysed locally at participating sites and in a central core laboratory in a portion of patients from PARAGON-B.

\section{Patient selection}

The study group included all patients with NSTE ACS from the respective trials who underwent $\mathrm{PCl}$ during the initial hospitalization. Patients who did not have CK-MB levels measured $<24 \mathrm{~h}$ after $\mathrm{PCl}$ and those who had a measured total CK or CK-MB level $>1$ times the upper limit of normal $(\times \mathrm{ULN})$ in the $24 \mathrm{~h}$ before $\mathrm{PCl}$ were excluded from the primary analysis. Patients with measured CK-MB levels had $\geq 1 \mathrm{CK}-\mathrm{MB}$ level recorded on the case report form within $24 \mathrm{~h}$ after $\mathrm{PCl}$.

\section{End-points}

The primary end-point of this analysis was all-cause mortality through 6 months, the longest common follow-up period among the trials. Additional in-hospital outcomes evaluated after $\mathrm{PCl}$ included congestive heart failure (new onset of dyspnoea with evidence of heart failure on physical examination), shock (persistent hypotension, diminished cardiac output, and evidence of end-organ hypoperfusion), and arrhythmias (ventricular fibrillation or tachycardia, atrial fibrillation or flutter, or advanced atrioventricular block). The incidence of (re)infarction after PCI was not evaluated, because repeat infarctions were not consistently collected and recorded among the trials when patients had multiple recurrent ischaemic events. Events occurring before $\mathrm{PCl}$ were not evaluated.

\section{Comparison groups}

Patients with $\geq 1 \mathrm{CK}-\mathrm{MB}$ level measured $<24 \mathrm{~h}$ after $\mathrm{PCl}$ were stratified into categories by peak CK-MB ratios of $0-1,1-3,3-5$, $5-10$, and $>10 \times U L N$ for statistical comparisons. The absolute peak CK-MB values for each patient were transformed into peak $C K-M B$ ratios with the following formula: peak CK-MB ratio=actual peak CK-MB value divided by the ULN for CK-MB from the local institution, according to expert recommendations. ${ }^{1,15}$ The clinical characteristics and outcomes of patients excluded from the primary analysis were not directly compared but were recorded to describe differences between excluded patients and the primary analysis group. Baseline characteristics of patients undergoing $\mathrm{PCl}$ from the different trials also were compared to assess differences across the populations.

\section{Statistical analysis}

Baseline, angiographic, and procedural characteristics are presented as numbers and percentages for categorical variables and as medians with 25th and 75th percentiles for continuous variables. Likelihood ratio chi-square, Mantel-Haenszel chisquare, Kruskal-Wallis, and Wilcoxon rank-sum tests were used to compare baseline categorical and continuous variables, respectively, among the comparison groups.

Kaplan-Meier event rates through 6 months were determined by peak CK-MB categories. Log-rank statistics were used to compare unadjusted clinical event rates among patients in the different peak CK-MB categories. We also determined the 
Table 1 Baseline clinical characteristics by trial enrolment for all patients undergoing PCI

\begin{tabular}{llllll}
\hline & $\begin{array}{l}\text { GUSTO-Ilb } \\
(n=1594)\end{array}$ & $\begin{array}{l}\text { PURSUIT } \\
(n=2226)\end{array}$ & $\begin{array}{l}\text { PARAGON-A } \\
(n=334)\end{array}$ & $\begin{array}{l}\text { PARAGON-B } \\
(n=1314)\end{array}$ & $\begin{array}{l}P \\
\text { value }\end{array}$ \\
\hline Age (years) & $62(54,70)$ & $62(53,69)$ & $64(55,70)$ & $61(52,70)$ & $0 \cdot 07$ \\
Male sex & $71.0 \%$ & $69 \cdot 3 \%$ & $72 \cdot 2 \%$ & $72 \cdot 1 \%$ & $0 \cdot 30$ \\
Heart rate (bpm) & $72(63,81)$ & $70(61,80)$ & $74(64,84)$ & $73(64,85)$ & $<0.001$ \\
Systolic BP (mmHg) & $137(120,150)$ & $130(115,142)$ & $144(130,160)$ & $140(125,160)$ & $<0.001$ \\
Diabetes & $18.6 \%$ & $20.2 \%$ & $13.2 \%$ & $21.7 \%$ & 0.002 \\
Enrolment infarction & $47.7 \%$ & $37.7 \%$ & $28.0 \%$ & $40.9 \%$ & $<0.001$ \\
Prior infarction & $26.9 \%$ & $29.1 \%$ & $30.5 \%$ & $28.2 \%$ & 0.37 \\
Prior PCI & $17.4 \%$ & $20.3 \%$ & $17.1 \%$ & $21.9 \%$ & 0.01 \\
Prior bypass surgery & $12.8 \%$ & $14.7 \%$ & $12.6 \%$ & $15.4 \%$ & 0.15 \\
Prior CHF & $3.3 \%$ & $6.7 \%$ & $3.9 \%$ & $8.1 \%$ & $<0.001$ \\
ECG findings & & & & $42.9 \%$ & $17.3 \%$ \\
$\quad$ ST depression & $54.0 \%$ & $30.6 \%$ & $60.7 \%$ & $45.9 \%$ & $<0.001$ \\
$\quad$ Transient ST elevation & $17.0 \%$ & $10.6 \%$ & $22.8 \%$ & $56.3 \%$ & $<0.001$ \\
T-wave inversion & $53.2 \%$ & $53.6 \%$ & & & $<0.001$ \\
\hline
\end{tabular}

${ }^{a}$ Across trials. $\mathrm{BP}=$ blood pressure; $\mathrm{PCl}=$ percutaneous coronary intervention; $\mathrm{CHF}=$ congestive heart failure; $\mathrm{ECG}=\mathrm{electrocardiographic}$.

unadjusted continuous relationship between peak CK-MB levels after $\mathrm{PCl}$ and 6-month mortality after transforming continuous peak CK-MB levels into splines. ${ }^{16}$

A multivariable regression model was developed from the PURSUIT database that reliably predicts 30 -day mortality among patients with NSTE ACS from eight baseline clinical characteristics (age, systolic blood pressure, heart rate, previous angina, male sex, ST-segment depression, enrolment infarction, and signs of congestive heart failure) that were shown to be the strongest predictors of mortality in a larger, expanded regression model. ${ }^{17}$ The variable 'signs of congestive heart failure' from the model was denoted as physical examination findings consistent with congestive heart failure upon hospital presentation. Variables added to the established model for this analysis included angiographic characteristics (two- and three-vessel coronary disease), unsuccessful $\mathrm{PCl}$ (stenosis $>50 \%$ or Thrombolysis In Myocardial Infarction [TIMI] grade $<3$ flow after PCI), experimental treatment (hirudin, eptifibatide, or lamifiban) as a dichotomous variable that denotes experimental treatment versus non-experimental treatment, time to $\mathrm{PCl}$, and peak $C K-M B$ ratio as a continuous variable (per one unit increase above ULN). Left ventricular ejection fraction could not be included in the multivariable model because it was not recorded on data-collection forms in 2470 of 5468 patients analysed (45.2\%). The continuous form of peak CK-MB levels was transformed into splines for incorporation into the model. ${ }^{16}$ Testing for linearity using the independent splines yielded nonsignificant results, hence the linearity assumption was satisfied and peak CK-MB ratio as a continuous variable was incorporated into the model in its true state with no transformations.

Based on Cox proportional-hazards modelling, Wald chisquare analyses were used to determine significant predictors of 6-month mortality and to test the statistical significance of the relationship of the continuous peak CK-MB ratio variable to 6-month mortality. Linear hypothesis testing was used to evaluate the relation of peak CK-MB ratio categories with 6-month mortality in a separately fitted version of the regression model rather than peak CK-MB ratio as a continuous variable. Interactions between the different categories of peak CK-MB ratios and time to death were tested to verify the proportional hazards assumption. Based upon non-significant $P$-values for these interactions, the assumption was considered to be valid.

An interaction term between experimental treatment and peak CK-MB ratio was incorporated into the regression model to evaluate the impact of the assigned treatments (hirudin, eptifibatide, or lamifiban) on the predictive capabilities of peak $\mathrm{CK}-\mathrm{MB}$ ratios. Experimental treatment was considered to be a dichotomous variable that denotes experimental treatment versus non-experimental treatment. Trial enrolment was not included in the final regression model because this variable depends linearly on experimental treatment, but a separately fitted version of the model that did not include experimental treatment showed no interaction between trial enrolment (using GUSTO-IIb as the reference) and peak CK-MB ratio categories (using the group with peak CK-MB ratios $0-1 \times U L N$ as the reference) with linear hypothesis testing (Wald chi square, 0.86 , $\mathrm{df}=3, P=0.83$ ).

\section{Results}

\section{Patients}

A total of 26,465 patients with NSTE ACS were enrolled in the four trials. About one-fourth of the patients $(23.3 \%)$ underwent $\mathrm{PCl}$ during the initial hospitalization $(n=6164)$. CK or CK-MB levels $<24 \mathrm{~h}$ before $\mathrm{PCl}$ were elevated in 696 patients, who were excluded. The primary analysis cohort included 2384 of the remaining 5468 patients (43.6\%) who had $\geq 1 \mathrm{CK}-\mathrm{MB}$ level measured $<24 \mathrm{~h}$ after $\mathrm{PCl}$. A total of 3084 patients (56.4\%) without CK-MB elevation before $\mathrm{PCl}$ did not have CK-MB levels measured after $\mathrm{PCl}$. The breakdown of patients with measured CK-MB levels after $\mathrm{PCl}$ from each trial included: 390 of 1594 patients from GUSTO-IIb (24.5\%), 1280 of 2226 patients from PURSUIT (57.5\%), 63 of 334 patients from PARAGON-A (18.9\%), and 651 of 1314 patients from PARAGON-B (49.5\%).

\section{Clinical, treatment, and procedural characteristics}

Clinical characteristics differed significantly across the trials among patients undergoing $\mathrm{PCl}$ (after excluding those with pre-procedural CK-MB elevations) (Table 1). In the combined dataset, the incidence of hypercholesterolemia, prior $\mathrm{PCI}$, previous angina, and $\mathrm{T}$-wave inversions 
Table 2 Baseline clinical characteristics by peak creatine kinase (CK)-MB ratio category

\begin{tabular}{|c|c|c|c|c|c|c|c|c|}
\hline & \multirow{2}{*}{$\begin{array}{l}\text { Not measured } \\
\text { after } \mathrm{PCl} \\
(n=3084)\end{array}$} & \multirow{2}{*}{$\begin{array}{l}>1 \times U L N, 24 \mathrm{~h} \\
\text { Pre-PCl } \\
(n=696)\end{array}$} & \multicolumn{5}{|c|}{ Peak CK-MB elevation after $\mathrm{PCI}, \times \mathrm{ULN}$} & \multirow[b]{2}{*}{$p^{a}$} \\
\hline & & & $\begin{array}{l}0-1 \\
(n=1335)\end{array}$ & $1-3(n=508)$ & $3-5(n=144)$ & $\begin{array}{l}5-10 \\
(n=170)\end{array}$ & $>10(n=227)$ & \\
\hline Age (years) & $62(53,70)$ & $59(51,69)$ & $61(52,68)$ & $62(53,69)$ & $62(54,69)$ & $62(53,70)$ & $62(50,72)$ & 0.46 \\
\hline Male sex & $71.5 \%$ & $73.6 \%$ & $67.9 \%$ & $69.7 \%$ & $70.1 \%$ & $72.9 \%$ & $70.9 \%$ & 0.46 \\
\hline Heart rate (per min) & $72(62,80)$ & $71(62,82)$ & $71(62,82)$ & $70(62,80)$ & $73(64,82)$ & $70(64,80)$ & $70(64,82)$ & 0.85 \\
\hline Systolic BP (mmHg) & $\begin{array}{l}136(120 \\
150)\end{array}$ & $\begin{array}{l}130(115, \\
148)\end{array}$ & $\begin{array}{l}132(120 \\
150)\end{array}$ & $\begin{array}{l}130(120 \\
150)\end{array}$ & $\begin{array}{l}130(118 \\
146)\end{array}$ & $\begin{array}{l}134(115, \\
150)\end{array}$ & $\begin{array}{l}130(116, \\
148)\end{array}$ & 0.05 \\
\hline Hypertension & $50.1 \%$ & $50.9 \%$ & $57.4 \%$ & $51.0 \%$ & $58.3 \%$ & $52.9 \%$ & $49.3 \%$ & 0.04 \\
\hline Diabetes & $18.7 \%$ & $18.7 \%$ & $21.9 \%$ & $18.3 \%$ & $22.9 \%$ & $21.8 \%$ & $20.7 \%$ & 0.53 \\
\hline Current smoking & $37.0 \%$ & $36.7 \%$ & $32.5 \%$ & $37.5 \%$ & $33.9 \%$ & $32.9 \%$ & $36.3 \%$ & 0.36 \\
\hline Hypercholesterolaemia & $48.0 \%$ & $47.0 \%$ & $51.4 \%$ & $48.5 \%$ & $50.4 \%$ & $47.1 \%$ & $37.2 \%$ & 0.003 \\
\hline Enrolment infarction & $39.6 \%$ & $84.0 \%$ & $31.1 \%$ & $47.3 \%$ & $59.0 \%$ & $57.5 \%$ & $72.8 \%$ & $<0.001$ \\
\hline Prior infarction & $28.1 \%$ & $26.7 \%$ & $29.4 \%$ & $30.1 \%$ & $25.2 \%$ & $24.3 \%$ & $23.9 \%$ & 0.22 \\
\hline Prior $\mathrm{PCl}$ & $18.3 \%$ & $19.1 \%$ & $22.2 \%$ & $22.3 \%$ & $20.8 \%$ & $29.2 \%$ & $15.9 \%$ & 0.04 \\
\hline Prior bypass surgery & $13.1 \%$ & $13.4 \%$ & $16.0 \%$ & $15.4 \%$ & $18.1 \%$ & $17.1 \%$ & $12.8 \%$ & 0.67 \\
\hline Prior CHF & $5.5 \%$ & $6.2 \%$ & $6.4 \%$ & $6.5 \%$ & $4.2 \%$ & $6.5 \%$ & $7.9 \%$ & 0.72 \\
\hline Previous angina & $74.8 \%$ & $65.8 \%$ & $83.3 \%$ & $83.1 \%$ & $76.4 \%$ & $77.7 \%$ & $70.0 \%$ & $<0.001$ \\
\hline \multicolumn{9}{|l|}{ ECG findings } \\
\hline ST depression & $45.8 \%$ & $36.9 \%$ & $33.0 \%$ & $39.2 \%$ & $37.1 \%$ & $40.6 \%$ & $46.5 \%$ & 0.001 \\
\hline Transient ST elevation & $15.2 \%$ & $17.3 \%$ & $12.5 \%$ & $12.9 \%$ & $15.6 \%$ & $21.9 \%$ & $21.0 \%$ & $<0.001$ \\
\hline T-wave inversion & $51.9 \%$ & $46.0 \%$ & $54.7 \%$ & $50.7 \%$ & $48.6 \%$ & 41.6 & $44.3 \%$ & $<0.001$ \\
\hline
\end{tabular}

${ }^{a}$ Across peak CK-MB ratio categories of $0-1,1-3,3-5,5-10$, and $>10 \times U L N$. ULN=upper limit of normal; $B P=b l o o d$ pressure; $P C l=$ percutaneous coronary intervention; $\mathrm{CHF}=$ congestive heart failure; $\mathrm{ECG}=$ electrocardiographic.

Table 3 Medication use by peak creatine kinase (CK)-MB ratio category

\begin{tabular}{|c|c|c|c|c|c|c|}
\hline & \multicolumn{5}{|c|}{ Peak CK-MB Elevation After PCI, ×ULN } & \multirow[b]{2}{*}{$P^{a}$} \\
\hline & $0-1(n=1335)$ & $1-3(n=508)$ & $3-5(n=144)$ & $5-10(n=170)$ & $>10(n=227)$ & \\
\hline \multicolumn{7}{|l|}{ In-hospital } \\
\hline Aspirin & $68.6 \%$ & $72.6 \%$ & $70.8 \%$ & $71.8 \%$ & $74.0 \%$ & 0.30 \\
\hline Beta-blockers & $52.7 \%$ & $58.3 \%$ & $56.3 \%$ & $55.3 \%$ & $58.1 \%$ & 0.20 \\
\hline ACE-inhibitors & $18.2 \%$ & $23.4 \%$ & $22.9 \%$ & $27.1 \%$ & $30.0 \%$ & $<0.001$ \\
\hline Anti-arrhythmics & $4.2 \%$ & $5.3 \%$ & $7.6 \%$ & $10.0 \%$ & $14.1 \%$ & $<0.001$ \\
\hline Lipid lowering agents & $21.4 \%$ & $18.5 \%$ & $19.4 \%$ & $21.8 \%$ & $18.9 \%$ & 0.64 \\
\hline \multicolumn{7}{|l|}{ Discharge } \\
\hline Aspirin & $66.0 \%$ & $68.0 \%$ & $64.6 \%$ & $68.2 \%$ & $67.3 \%$ & 0.89 \\
\hline Beta-blockers & $44.7 \%$ & $48.2 \%$ & $43.1 \%$ & $45.9 \%$ & $46.3 \%$ & 0.69 \\
\hline ACE-inhibitors & $16.0 \%$ & $20.1 \%$ & $19.4 \%$ & $22.4 \%$ & $26.9 \%$ & 0.001 \\
\hline Anti-arrhythmics & $1.8 \%$ & $1.2 \%$ & $2.1 \%$ & $4.1 \%$ & $2.2 \%$ & 0.19 \\
\hline Lipid lowering agents & $23.0 \%$ & $21.5 \%$ & $22.9 \%$ & $24.7 \%$ & $18.1 \%$ & 0.47 \\
\hline
\end{tabular}

${ }^{a}$ Across peak CK-MB ratio categories of $0-1,1-3,3-5,5-10$, and >10×ULN. PCl=percutaneous coronary intervention; ULN=upper limit of normal; $\mathrm{ACE}=$ angiotensin converting enzyme.

on the presenting ECG decreased with higher peak CK-MB ratios (Table 2). The incidence of enrolment MI, STsegment depression, and transient ST-segment elevation increased with higher peak CK-MB categories. In-hospital and discharge medication use was similar across the peak CK-MB categories except for greater use of angiotensinconverting enzyme (ACE) inhibitors and in-hospital antiarrhythmic medications in patients with higher peak CK-MB ratios (Table 3)

Angiographic findings showed that patients with higher peak CK-MB ratios more commonly had multivessel coronary disease, impaired left ventricular systolic func- tion, and lower rates of procedural success (Table 4). The median time to $\mathrm{PCl}$ was shorter in patients with higher peak CK-MB ratios.

\section{Unadjusted clinical outcomes}

The unadjusted frequencies of death, congestive heart failure, cardiogenic shock, and arrhythmias during the initial hospitalization were increased with higher peak CK-MB ratio categories, but the highest in-hospital mortality rate was seen in the group with peak CK-MB rations 
Table 4 Angiographic and procedural characteristics by peak creatine kinase (CK)-MB ratio category

\begin{tabular}{|c|c|c|c|c|c|c|c|c|}
\hline & \multirow{2}{*}{$\begin{array}{l}\text { Not measured } \\
\text { after } \mathrm{PCl} \\
(n=3084)\end{array}$} & \multirow{2}{*}{$\begin{array}{l}>1 \times U L N, 24 \mathrm{~h} \\
\text { Pre-PCI } \\
(n=696)\end{array}$} & \multicolumn{5}{|c|}{ Peak CK-MB elevation after $\mathrm{PCI}, \times \mathrm{ULN}$} & \multirow[b]{2}{*}{$P^{a}$} \\
\hline & & & $\begin{array}{l}0-1 \\
(n=1335)\end{array}$ & $\begin{array}{l}1-3 \\
(n=508)\end{array}$ & $\begin{array}{l}3-5 \\
(n=144)\end{array}$ & $\begin{array}{l}5-10 \\
(n=170)\end{array}$ & $\begin{array}{l}>10 \\
(n=227)\end{array}$ & \\
\hline No. diseased vessels & & & & & & & & 0.005 \\
\hline One & $52.0 \%$ & $47.7 \%$ & $51.1 \%$ & $47.5 \%$ & $46.6 \%$ & $45.9 \%$ & $45.1 \%$ & \\
\hline Two & $30.4 \%$ & $31.8 \%$ & $30.2 \%$ & $32.4 \%$ & $27.8 \%$ & $28.3 \%$ & $30.9 \%$ & \\
\hline Three & $16.9 \%$ & $20.1 \%$ & $18.3 \%$ & $20.1 \%$ & $25.6 \%$ & $25.2 \%$ & $24.0 \%$ & \\
\hline LV systolic function ${ }^{\mathrm{b}}$ & & & & & & & & $<0.001$ \\
\hline Normal, EF >55\% & $56.0 \%$ & $37.4 \%$ & $57.2 \%$ & $47.9 \%$ & $52.3 \%$ & $55.5 \%$ & $30.8 \%$ & \\
\hline Mild, EF $40-55 \%$ & $31.8 \%$ & $44.4 \%$ & $31.3 \%$ & $33.5 \%$ & $36.1 \%$ & $29.7 \%$ & $44.6 \%$ & \\
\hline Moderate, EF $30-40 \%$ & $8.2 \%$ & $13.8 \%$ & $8.4 \%$ & $11.3 \%$ & $9.3 \%$ & $9.9 \%$ & $17.7 \%$ & \\
\hline Severe, EF $<30 \%$ & $4.0 \%$ & $4.4 \%$ & $3.1 \%$ & $7.4 \%$ & $2.3 \%$ & $5.0 \%$ & $6.9 \%$ & \\
\hline $\begin{array}{l}\text { Median time to } \mathrm{PCl}, \mathrm{h} \\
\text { Devices used }\end{array}$ & $119(69,211)$ & $29(20,29)$ & $70(26,138)$ & $57(13,120)$ & $28(4,94)$ & $20(3,91)$ & $7(2,69)$ & $<0.001$ \\
\hline Angioplasty only & $57.6 \%$ & $38.4 \%$ & $42.0 \%$ & $42.1 \%$ & $43.1 \%$ & $48.8 \%$ & $48.5 \%$ & 0.22 \\
\hline Stent & $37.9 \%$ & $59.2 \%$ & $55.8 \%$ & $54.1 \%$ & $50.7 \%$ & $50.0 \%$ & $48.0 \%$ & 0.15 \\
\hline Other device ${ }^{d}$ & $4.4 \%$ & $5.0 \%$ & $5.6 \%$ & $5.3 \%$ & $6.9 \%$ & $5.3 \%$ & $6.6 \%$ & 0.91 \\
\hline Procedural success ${ }^{\mathrm{e}}$ & $65.0 \%$ & $95.0 \%$ & $88.6 \%$ & $81.7 \%$ & $76.8 \%$ & $76.7 \%$ & $64.9 \%$ & $<0.001$ \\
\hline
\end{tabular}

a Across peak CK-MB ratio categories of $0-1,1-3,3-5,5-10$, and $>10 \times$ ULN .

${ }^{\mathrm{b}}$ Ejection fraction recorded in 2470 of 5468 patients.

${ }^{\mathrm{c}}$ Not mutually exclusive.

dIncludes atherectomy, rotablation, laser angioplasty, or extraction catheters. Does not include distal protection devices.

e Postintervention TIMI grade 3 flow or lesion stenosis $<50 \%$. PCl=percutaneous coronary intervention; ULN=upper limit of normal; LV=left ventricular; $E F=e j e c t i o n$ fraction

Table 5 Unadjusted clinical outcomes by peak creatine kinase (CK)-MB ratio category

\begin{tabular}{|c|c|c|c|c|c|c|c|c|}
\hline & \multirow{2}{*}{$\begin{array}{l}\text { Not measured } \\
\text { after PCI } \\
(n=3084)\end{array}$} & \multirow{2}{*}{$\begin{array}{l}>1 \times U L N, 24 \mathrm{~h} \\
\text { Pre-PCI } \\
(n=696)\end{array}$} & \multicolumn{5}{|c|}{ Peak CK-MB elevation after $\mathrm{PCI}, \times \mathrm{ULN}$} & \multirow[b]{2}{*}{$P^{a}$} \\
\hline & & & $\begin{array}{l}0-1 \\
(n=1335)\end{array}$ & $\begin{array}{l}1-3 \\
(n=508)\end{array}$ & $\begin{array}{l}3-5 \\
(n=144)\end{array}$ & $\begin{array}{l}5-10 \\
(n=170)\end{array}$ & $\begin{array}{l}>10 \\
(n=227)\end{array}$ & \\
\hline \multicolumn{9}{|l|}{ In-hospital } \\
\hline Mortality & $0.5 \%$ & $0.9 \%$ & $0.3 \%$ & $1.0 \%$ & $4.2 \%$ & $2.4 \%$ & $2.6 \%$ & 0.001 \\
\hline Heart failure & $0.4 \%$ & $1.0 \%$ & $0.1 \%$ & $0.8 \%$ & $3.4 \%$ & $4.1 \%$ & $6.1 \%$ & $<0.001$ \\
\hline Cardiogenic shock & $0.2 \%$ & $0.4 \%$ & $0.1 \%$ & $1.3 \%$ & $2.0 \%$ & $2.3 \%$ & $2.6 \%$ & 0.004 \\
\hline Arrhythmias $^{\mathrm{b}}$ & $1.0 \%$ & $3.3 \%$ & $0.8 \%$ & $1.9 \%$ & $6.9 \%$ & $4.1 \%$ & $7.9 \%$ & $<0.001$ \\
\hline \multicolumn{9}{|l|}{30 Days } \\
\hline Mortality & $0.8 \%$ & $1.4 \%$ & $0.7 \%$ & $1.2 \%$ & $4.2 \%$ & $2.9 \%$ & $3.1 \%$ & $<0.001$ \\
\hline \multicolumn{9}{|l|}{6 Months } \\
\hline Mortality & $1.3 \%$ & $2.6 \%$ & $2.1 \%$ & $2.4 \%$ & $4.9 \%$ & $4.1 \%$ & $5.7 \%$ & 0.005 \\
\hline Repeat intervention & $24.0 \%$ & $8.3 \%$ & $10.4 \%$ & $15.6 \%$ & $20.1 \%$ & $12.9 \%$ & $23.8 \%$ & $<0.001$ \\
\hline Bypass surgery & $2.3 \%$ & $5.6 \%$ & $3.5 \%$ & $6.9 \%$ & $4.9 \%$ & $8.8 \%$ & $5.7 \%$ & 0.02 \\
\hline
\end{tabular}

a Across peak CK-MB ratio categories of $0-1,1-3,3-5,5-10$, and $>10 \times U$ LN .

bIncludes ventricular tachycardia or fibrillation, atrial fibrillation or flutter, and atrioventricular block. $\mathrm{PCl}=$ percutaneous coronary intervention; ULN=upper limit of normal.

3-5×ULN (Table 5). Cumulative mortality rates through 30 days and 6 months were also increased with higher peak CK-MB ratio categories and the highest 6-month mortality rate seen in the group with peak CK-MB ratios $>10 \times U L N$. While there was a marginally significant difference in 6-month mortality rates among the groups with peak CK-MB ratios of 3-5, 5-10, and $>10 \times U L N$ (three-way $P$-value $=0.0498)$, Kaplan-Meier mortality curves showed early separation between these peak CK-MB categories and the lower peak CK-MB categories (Table 5 and Fig. 1). The continuous relationship of peak CK-MB ratio with 6-month mortality demonstrated that higher peak CK-MB ratios were associated with a greater risk of 6-month mortality compared with lower levels of CK-MB elevation (Fig. 2).

\section{Multivariable predictors of mortality}

After adjustment for clinical, angiographic, and treatment characteristics, age, three-vessel coronary disease, unsuccessful $\mathrm{PCl}$, peak $\mathrm{CK}-\mathrm{MB}$ ratio as a continuous variable, and previous angina were significant predictors of 6-month mortality (Table 6). The interaction term between experimental treatment versus placebo and peak 


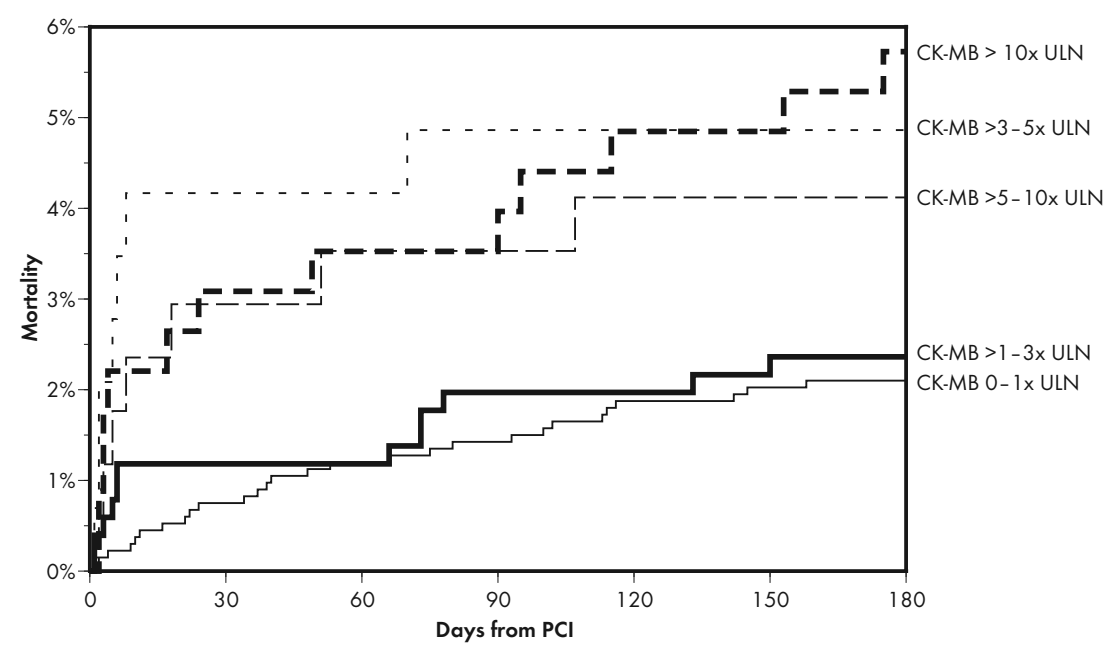

Fig. 1 Kaplan-Meier curves for unadjusted mortality after percutaneous coronary intervention through 6 months, for increments of periprocedural peak creatine kinase (CK)-MB elevation as a multiple of the upper limit of normal $(\times \mathrm{ULN})$.

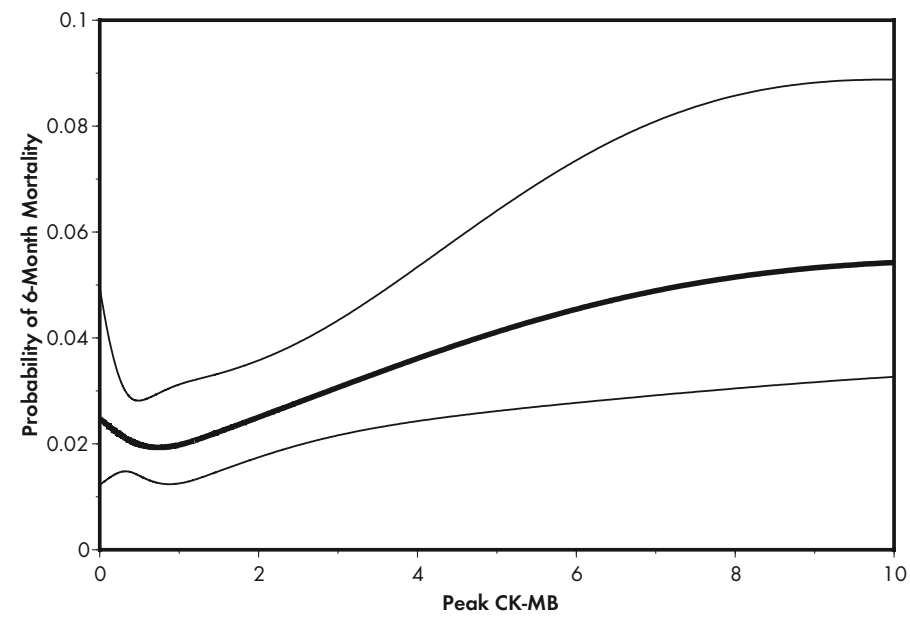

Fig. 2 Continuous, unadjusted relationship between peak creatine kinase (CK)-MB, as a multiple of the upper limit of normal, and 6-month mortality. Thin lines represent $95 \%$ confidence intervals.

CK-MB ratio was not significant (risk ratio [RR], 1.02; 95\% confidence interval $[\mathrm{Cl}], 0.94-1.12 ; P=0.58$ ) and was therefore dropped from the model.

When peak CK-MB ratios were analysed by distinct categories in the regression model, linear hypothesis testing revealed a non-significant trend for an association for an increased risk of 6-month mortality with higher peak CK-MB categories (Wald chi square, 8.63; $\mathrm{df}=4$, $P=0.07)$. The adjusted risk of 6 -month mortality was not increased significantly with peak CK-MB ratios of $1-3 \times \operatorname{ULN}(\mathrm{RR}, 1.15 ; 95 \% \mathrm{Cl}, 0.53-2.48 ; P=0.72)$ compared with the reference group of peak CK-MB ratios of $0-1 \times U L N$, but was increased to similar extents with peak CK-MB ratios of $3-5 \times U L N(R R, 2.82 ; 95 \% \mathrm{Cl}, 1.11-7.16$; $P=0.03$ ), 5-10×ULN (RR, 2.64; 95\% Cl, 1.04-6.72; $P=0.04)$, and $>10 \times \operatorname{ULN}(\mathrm{RR}, 2.13 ; 95 \% \mathrm{Cl}, 0.91-4.96 ; P=0.08)$.

\section{Discussion}

We have shown an association between higher levels of peak CK-MB elevation after $\mathrm{PCl}$ and an increased risk of adverse outcomes in patients with NSTE ACS. This study provides unique insight into the relationship between periprocedural myocardial necrosis and adverse clinical outcomes, given that peak CK-MB levels after $\mathrm{PCl}$ were analysed both continuously and categorically in a highrisk population that was previously not well-studied. Furthermore, the prognostic implications of periprocedural CK-MB elevations were confirmed with an expanded version of a validated multivariable regression model that also adjusted for angiographic and procedural factors known to be significant predictors of mortality. Therefore, these results further highlight the adverse 
Table 6 Multivariable predictors of 6-month mortality

\begin{tabular}{|c|c|c|c|}
\hline Variable & Wald chi square & Risk ratio ( $95 \%$ confidence interval) & $P$ value \\
\hline $\operatorname{Age}^{a}$ & 10.99 & $1.06(1.02-1.09)$ & $<0.001$ \\
\hline Three-vessel coronary disease & 10.43 & $3.36(1.61-7.02)$ & 0.001 \\
\hline Unsuccessful procedure ${ }^{\mathrm{b}}$ & 6.47 & $2.46(1.23-4.93)$ & 0.011 \\
\hline Peak creatine kinase $(C K)-M B$ ratio ${ }^{a}$ & 5.66 & $1.06(1.01-1.11)$ & 0.017 \\
\hline Previous angina & 3.98 & $7.98(1.04-61.35)$ & 0.05 \\
\hline Male sex & 2.23 & $1.47(0.89-2.44)$ & 0.14 \\
\hline ST-segment depression & 1.58 & $0.64(0.32-1.28)$ & 0.21 \\
\hline Heart rate ${ }^{a}$ & 1.27 & $1.01(0.99-1.03)$ & 0.26 \\
\hline Systolic blood pressure ${ }^{a}$ & 1.26 & $0.99(0.98-1.00)$ & 0.26 \\
\hline Signs of congestive heart failure & 0.83 & $1.51(0.62-3.67)$ & 0.36 \\
\hline Experimental treatment ${ }^{\mathrm{c}}$ & 0.57 & $1.28(0.68-2.40)$ & 0.45 \\
\hline Enrolment infarction & 0.48 & $0.79(0.40-1.56)$ & 0.49 \\
\hline Time to percutaneous coronary intervention & 0.12 & $1.00(0.99-1.01)$ & 0.73 \\
\hline Two-vessel coronary disease & 0.05 & $0.90(0.37-2.20)$ & 0.82 \\
\hline
\end{tabular}

${ }^{a}$ Continuous variables.

b Stenosis $>50 \%$ or TIMI grade $<3$ flow after the procedure.

${ }^{\mathrm{c}}$ Hirudin, eptifibatide, or lamifiban.Overall model chi square, 64.12 with 14 degrees of freedom.

prognostic implications of periprocedural myocardial necrosis and underscore the importance of routine surveillance of CK-MB levels after $\mathrm{PCl}$.

Despite the demonstrated association between periprocedural myocardial necrosis and mortality, the pathophysiological mechanisms underlying cardiac enzyme elevation and subsequent adverse clinical outcomes remain controversial. Periprocedural necrosis is often caused by procedural complications such as sidebranch occlusion, abrupt closure, or coronary dissection. ${ }^{6,18}$ Our results show a correlation between lower rates of procedural success and higher peak CK-MB levels after $\mathrm{PCI}$, but embolization of atherosclerotic and thrombotic material to the distal coronary circulation is thought to occur commonly during $\mathrm{PCl}$, even without obvious procedural complications. ${ }^{7}$ Contrast-enhanced magnetic resonance imaging has shown that patients with minor CK-MB elevations after uncomplicated $\mathrm{PCI}$ have regions of hyper-enhancement within the perfusion territory of the target vessel, corresponding to small infarctions that may be caused by embolization of small amounts of thrombus not seen on angiography. ${ }^{19}$ However, greater atherosclerotic plaque burden has been shown to be associated with an increased likelihood of periprocedural CK-MB release in this analysis and other studies, so cardiac enzyme elevations after $\mathrm{PCI}$ may also be a marker of high-risk features in patients without an obvious MI. ${ }^{20,21}$ Thus, although a definite cause-andeffect relation between periprocedural myocardial necrosis and later adverse outcomes has not been shown, CK-MB elevations after $\mathrm{PCI}$ have clear adverse prognostic implications for risk stratification of patients with NSTE ACS undergoing $\mathrm{PCl}$.

Although the degree of periprocedural myocardial necrosis appears to be related quantitatively to the risk of adverse outcomes, the classification and definition of periprocedural MI has been extensively debated. ${ }^{1,2,4,5,15}$ We evaluated periprocedural CK-MB levels in a continuous fashion and showed an association between the risk of mortality and higher levels of CK-MB elevation (above a threshold with low peak CK-MB ratios). Furthermore, the association between peak CK-MB levels and mortality was not as strong when peak CK-MB ratios were analysed as distinct categories in the regression model, perhaps due to the relatively small numbers of patients in each category. Recent retrospective studies have suggested that only major categories of CK-MB elevations $(>5-$ $10 \times U L N$ ) delineate an independent contribution to mortality risk after elective $\mathrm{PCl}$, but patients with lower levels of CK-MB elevations did have a slightly higher risk of mortality in these studies and the risk associated with CK-MB levels was not evaluated in a continuous fashion. ${ }^{22-24}$ However, consensus statements suggest that any degree of $\mathrm{CK}-\mathrm{MB}$ elevation after $\mathrm{PCl}$ is associated with adverse prognostic implications., ${ }^{15}$ Therefore, CK-MB elevation after $\mathrm{PCl}$ appears to be associated with a continuum of risk, but further analyses are needed to clearly define a clinically useful threshold of CK-MB elevation for risk stratification of patients undergoing $\mathrm{PCl}$.

The definition of MI has evolved with the introduction of new cardiac markers, such as the troponins I and $\mathrm{T}$, but distinctions between spontaneous and periprocedural myocardial damage in patients with ACS remain poorly characterized. ${ }^{25}$ The degree of spontaneous CK-MB elevation in patients with ACS who do not undergo revascularization correlates with an increased risk of adverse outcomes, and infarctions that occur after hospital admission are associated with an even greater risk of mortality than are infarctions present at admission. ${ }^{26,27}$ In this analysis, patients with elevated CK-MB levels after $\mathrm{PCl}$ had a higher risk of mortality compared with patients with elevated CK or CK-MB levels $<24 \mathrm{~h}$ before $\mathrm{PCl}$, indicating that periprocedural myocardial necrosis may confer a worse prognosis than spontaneous necrosis from the presenting ischaemic event. ${ }^{27}$ Furthermore, periprocedural CK-MB elevation may reflect greater cumulative myocardial damage in 
ACS patients with spontaneous myocardial necrosis and may partly explain the adverse consequences of postadmission infarctions. ${ }^{27}$ Although larger, prospective studies are needed to determine the ideal thresholds and markers for the classification of spontaneous and periprocedural infarctions in patients with ACS, the long-term risks of myocardial necrosis appear to be similar irrespective of the mechanism of ischaemic insult. 2,3,7,15,27

Although this study represents the largest evaluation of periprocedural CK-MB elevations in patients with ACS, it has several limitations. First, because CK-MB sampling after $\mathrm{PCl}$ was not mandated by the study protocols, the sample size was limited and a selection bias was present, in that CK-MB levels may have been measured only in higher-risk patients. However, other contemporary ACS databases do not include routine cardiac enzyme data in all patients after $\mathrm{PCl}$, so this analysis represents the largest accumulation of periprocedural CK-MB data in patients with ACS. We also presented results for patients who did not have CK-MB levels measured after $\mathrm{PCl}$ in an attempt to account for this selection bias. Second, patients with myocardial necrosis before $\mathrm{PCl}$ may have been misidentified as having periprocedural infarctions. Although we excluded patients with elevated CK or CK-MB levels $<24 \mathrm{~h}$ before $\mathrm{PCl}$ to limit confounding from spontaneous infarctions, the median time to $\mathrm{PCl}$ was progressively shorter with higher peak CK-MB ratios. This suggests that patients with large CK-MB elevations after $\mathrm{PCl}$ may have had spontaneous infarctions at arrival that were not identified before $\mathrm{PCl}$ was performed. Third, we could not assess the impact of symptoms of ischaemia, ECG changes, or detailed angiographic complications on the unfavourable prognosis associated with periprocedural CK-MB elevations, because these data were not systematically collected. Fourth, distal protection devices have been shown to limit embolization of atherosclerotic and thrombotic debris to the coronary microcirculation and reduce the incidence of periprocedural infarctions. ${ }^{28}$ However, distal protection devices were not clinically available during the time periods of these studies (1994-1999), so we could not assess the impact of these devices on our findings. ${ }^{10-12,14}$ Fifth, we could not adjust for ejection fraction in the regression model because it was not recorded on the case report form in almost half of the patients. However, the regression model did include the variable 'signs of congestive heart failure', which represented the clinical manifestations of left ventricular dysfunction. Sixth, differences among the trial populations may have influenced the results, but the inclusion criteria of the trials were similar and there was no interaction between trial enrolment and peak CK-MB ratio in the regression model. Finally, glycoprotein IIb/IIla inhibitors reduce periprocedural CK-MB elevations and could therefore have limited CK-MB release after $\mathrm{PCl}$, but there was no interaction between experimental treatment and peak CK-MB ratio in the regression model to indicate that such treatment affected the findings.

\section{Conclusions}

In summary, periprocedural CK-MB elevation was independently associated with an increased risk of mortality and other early adverse outcomes in patients with NSTE-ACS, but a definite cause and effect relationship was not established. However, these results suggest that risk stratification of ACS patients should include routine surveillance of CK-MB levels after $\mathrm{PCl}$ to assess an individual patient's risk of adverse outcomes and that independent adjudication of suspected periprocedural ischaemic events should be incorporated into end-point definitions for clinical trials that include ACS patients. ${ }^{13}$

\section{Acknowledgements}

This study was funded in part by a grant from Millennium Pharmaceuticals, Inc., Cambridge, Massachusetts, USA.

\section{References}

1. Califf RM, Abdelmeguid AE, Kuntz RE et al. Myonecrosis after revascularization procedures. J Am Coll Cardiol 1998;31:241-51.

2. Harrington RA. Cardiac enzyme elevations after percutaneous coronary intervention: myonecrosis, the coronary microcirculation, and mortality. J Am Coll Cardiol 2000;35:1142-4.

3. Holmes DR Jr, Berger PB. Troponisms, necrosettes, enzyme leaks, creatine phosphokinase bumps, and infarclets: what's behind this new lexicon and what does it add? Circulation 2001;104:627-9.

4. Kong TQ, Davidson CJ, Meyers SN et al. Prognostic implication of creatine kinase elevation following elective coronary artery interventions. JAMA 1997;277:461-6.

5. Abdelmeguid AE, Topol EJ, Whitlow PL et al. Significance of mild transient release of creatine kinase-MB fraction after percutaneous coronary interventions. Circulation 1996;94:1528-36.

6. Tardiff BE, Califf RM, Tcheng JE et al. Clinical outcomes after detection of elevated cardiac enzymes in patients undergoing percutaneous coronary intervention. J Am Coll Cardiol 1999;33:88-96.

7. Topol EJ, Yadav JS. Recognition of the importance of embolization in atherosclerotic vascular disease. Circulation 2000;101:570-80.

8. Harrington RA, Califf RM, Holmes DR Jr et al. Is all unstable angina the same? insights from the Coronary Angioplasty Versus Excisional Atherectomy Trial (CAVEAT-1). Am Heart J 1999;137:227-33.

9. Thel MC, Califf RM, Tardiff BE et al. Timing and risk factors for myocardial ischemic events after percutaneous coronary intervention (IMPACT-II). Am J Cardiol 2000;85:427-35.

10. The GUSTO-IIb Investigators. A comparison of recombinant hirudin with heparin for the treatment of acute coronary syndromes. N Engl $J$ Med 1996;335:775-82.

11. The PURSUIT Investigators. Inhibition of platelet glycoprotein IIb/IIla with eptifibatide in patients with acute coronary syndromes. N Engl J Med 1998;339:436-43.

12. The PARAGON Investigators. International, randomized, controlled trial of lamifiban (a platelet glycoprotein Ilb/IIla inhibitor), heparin, or both in unstable angina. Circulation 1998;97:2386-95.

13. Mahaffey KW, Harrington RA, Akkerhuis $M$ et al. Disagreements between a central clinical events committee and site investigator assessments of myocardial infarction end points in an international clinical trial: review of the PURSUIT study. Curr Control Trials Cardiovasc Med 2001;2:187-94.

14. The PARAGON-B Investigators. Randomized, placebo-controlled trial of titrated intravenous lamifiban for acute coronary syndromes. Circulation 2002;105:316-21.

15. Alpert JS, Thygesen K. Myocardial infarction redefined - a consensus document of the joint European Society of Cardiology/American College of Cardiology Committee for the Redefinition of Myocardial Infarction. J Am Coll Cardiol 2000;36:959-69.

16. Smith PL. Splines as a useful and convenient statistical tool. Am Statistician 1979;33:57-62. 
17. Boersma E, Pieper KS, Steyerberg EW et al. Predictors of outcome in patients with acute coronary syndromes without persistent STsegment elevation. Results from an international trial of 9461 patients. Circulation 2000;101:2557-67.

18. Stone GW, Mehran R, Dangas G et al. Differential impact on survival of electrocardiographic Q-wave versus enzymatic myocardial infarction after percutaneous intervention: a device-specific analysis of 7147 patients. Circulation 2001;104:642-7.

19. Riccardi MJ, Wu E, Davidson CJ et al. Visualization of discrete microinfarction after percutaneous coronary intervention associated with mild creatine kinase-MB elevation. Circulation 2001;103: 2780-3.

20. Kanaparti PK, Brown DL. Relation between coronary atherosclerotic plaque burden and cardiac enzyme elevation following percutaneous coronary intervention. Am J Cardiol 2000;86:619-22.

21. Mehran R, Dangas G, Mintz GS et al. Atherosclerotic plaque burden and CK-MB enzyme elevation after coronary interventions: intravascular ultrasound study of 2256 patients. Circulation 2000; 101:604-10.

22. Sacuedo JF, Mehran R, Dangas G et al. Long-term clinical events following creatine kinase-myocardial band isoenzyme elevation after successful coronary stenting. J Am Coll Cardiol 2000; 35:1134-41.

23. Ellis SG, Chew D, Chan A et al. Death following creatine kinase-MB elevation after coronary intervention. Circulation 2002;106: 1205-10.

24. Brener SJ, Lytle BW, Schneider JP et al. Association between CK-MB elevation after percutaneous or surgical revascularization and threeyear mortality. J Am Coll Cardiol 2002;40:1961-7.

25. Akkerhuis KM, Alexander JH, Tardiff BE et al. Minor myocardial damage and prognosis: are spontaneous and percutaneous coronary intervention-related events different? Circulation 2002;105: 554-6.

26. Cantor WJ, Newby LK, Christenson RH et al. Prognostic significance of elevated troponin I after percutaneous coronary intervention. J Am Coll Cardiol 2002;89:1738-44.

27. Alexander JH, Sparapani RA, Mahaffey KW et al. Association between minor elevations of creatine kinase-MB level and mortality in patients with acute coronary syndromes without ST-segment elevation. JAMA 2000;283:347-53.

28. Morales PA., Heuser RR. Embolic protection devices. J Interv Cardiol 2002;15:485-90. 